\title{
The Dimensions of Cyanobacterial Gas Vesicles in Relation to Their Efficiency in Providing Buoyancy and Withstanding Pressure
}

\author{
By A. E. WALSBY* AND A. BLEYTHING \\ Department of Botany, University of Bristol, Woodland Road, Bristol BS8 1UG, UK
}

(Received 18 February 1988; revised 30 May 1988)

\begin{abstract}
The lengths and cylinder diameters of gas vesicles isolated from eight cyanobacteria were determined by electron microscopy. From these measurements the volumes and buoyant densities of the gas vesicles were calculated. A quantitative analysis was made of the effects of length and diameter on efficiency in providing buoyancy. In seven of the cyanobacteria the mean length exceeded that which would give $90 \%$ of the maximum efficiency. It is postulated that the mean diameter $(d)$ in each organism is constrained by the requirement for a particular critical pressure $\left(p_{\mathrm{c}}\right)$ to withstand the combination of turgor pressure and hydrostatic pressure experienced in the natural habitat, such that $d=59\left(p_{\mathrm{c}} / \mathrm{MPa}\right)^{-0.56} \mathrm{~nm}$. The mean diameter of gas vesicles from Anabaena flos-aquae was estimated to be $84.0 \mathrm{~nm}$ with a standard deviation of $4 \cdot 1 \mathrm{~nm}$. The weakest $10 \%$ of the vesicles had a diameter $6.2 \mathrm{~nm}$ wider than the strongest $10 \%$, indicating that the variation was not an artifact of measurement. The intrinsic variation in width accounts for about a third of the observed critical pressure variation. The width of new gas vesicles formed in cells of Anabaena flos-aquae grown in $100 \mathrm{mM}$-sucrose, which reduced turgor pressure by half (to $0.17 \mathrm{MPa}$ ), was only marginally greater than in normal conditions, and it is concluded that the mean width is genetically determined and not directly altered by pressure.
\end{abstract}

\section{INTRODUCTION}

Many planktonic cyanobacteria and other aquatic bacteria derive their buoyancy from gas vesicles, which are hollow structures formed from proteins known as gas vesicle protein (GVP). The economy of providing buoyancy by gas vesicles can be related to the amount of protein that is required to enclose a given amount of gas space. The width of gas vesicles varies in different groups of prokaryotes; those of the halobacteria are widest and, as they have the same thickness of wall protein, they must have the lowest buoyant density and provide buoyancy with greatest economy (Walsby, 1971). The critical collapse pressure of a gas vesicle varies inversely as a function of its width, and this factor has clearly influenced the evolution of gas vesicles in different prokaryotes. Narrower, stronger gas vesicles are found in organisms that possess high cell turgor pressures and live in deep waters (Walsby, 1972). A higher ratio of GVP to gas space, and lower efficiency in providing buoyancy, is therefore the penalty that must be paid for the increased strength required to withstand greater pressures.

The gas vesicles of cyanobacteria were once considered to have approximately the same cylinder diameter, 65 to $75 \mathrm{~nm}$ (e.g. Bowen \& Jensen, 1965; Jost, 1965; Smith \& Peat, 1967; Jost \& Jones, 1970), a range that might have been explained by the error of measurement by electron microscopy (Walsby, 1972). Hayes \& Walsby (1986) have recently demonstrated, however, that the gas vesicles of five genera of cyanobacteria show significantly different cylinder diameters, ranging from $64 \mathrm{~nm}$ to $107 \mathrm{~nm}$, and that the mean critical pressures of these gas vesicles are inversely related to their widths. There was, moreover, found to be a correlation between the critical pressure of gas vesicles in each organism and the pressure that they were likely to encounter in the natural habitat. Hayes \& Walsby (1986) proposed that there had been natural

Abbreviation: GVP, gas vesicle protein. 
selection of gas vesicles with the maximum width allowed by the requirement to withstand pressure.

We have extended the investigation of Hayes \& Walsby (1986) by making length as well as width measurements on the gas vesicles of eight different cyanobacteria. From these data we have been able to determine the buoyant densities of gas vesicles, which can be related directly to their efficiency in providing buoyancy. The measurements made by Hayes \& Walsby (1986) suggested that within each organism there was a small variation in gas vesicle cylinder diameter but they did not eliminate the possibility that these differences were artifacts caused by shrinkage or stretching during the preparation for electron microscopy. We have now demonstrated that genuine differences in diameter do exist, and that they account for part of the range of critical pressure of gas vesicles in a given organism.

If there are variations in the width of gas vesicles in a given organism it is possible that the width of individual gas vesicles might be regulated in some way. Economies in gas vesicle production could be achieved by making wider and hence weaker gas vesicles that survive under combinations of low hydrostatic and turgor pressure. We have therefore investigated the effect of lowering cell turgor pressure on the size of gas vesicles subsequently produced.

\section{METHODS}

Cyanobacteria and culture conditions. The cyanobacteria used are listed in Tables 1 and 2 . They were grown in illuminated incubators at $20^{\circ} \mathrm{C}$, except for Dactylococcopsis salina, which was grown at $32{ }^{\circ} \mathrm{C}$. The culture media used were medium B + N of Armstrong et al. (1983) for Nostoc muscorum, medium BG11 of Rippka et al. (1979) for Microcystis sp. and Calothrix sp., and the media described by Walker et al. (1984) for the other cyanobacteria.

Gas vesicle isolation. Intact gas vesicles were isolated by the methods described previously for species of Dactylococcopsis, Oscillatoria, Anabaena, Aphanizomenon (Walker et al., 1984), Microcystis and Calothrix (Hayes \& Walsby, 1986). Gas vesicles of Nostoc muscorum were prepared after lysing the cells with $0.7 \mathrm{M}$-sucrose, as for Anabaena (Walsby, 1974).

Electron microscopy. Isolated gas vesicles were prepared for electron microscopy by making platinum/carbonshadowed replicas as described by Hayes \& Walsby (1986). The gas vesicle replicas were photographed in a JEOL 1200-EX electron microscope at a magnification of about 20000. The exact magnification of each micrograph was determined by photographing a calibrated diffraction grating replica immediately after each micrograph. A particular marked square of the diffraction grating grid (Agar Aids grating with nominal spacing of 2160 lines $\mathrm{mm}^{-1}$ ) was brought into focus with the mechanical stage, ' $z$ ' control of the electron microscope; this avoided refocusing with the lens current controls, which otherwise would have caused small magnification changes. The magnification of this 'sister' negative was determined by measuring the distance across the image of diffraction grating rulings with the vernier microscope. The images of gas vesicles on the corresponding micrograph negative, which were between 1.2 and $2.5 \mathrm{~mm}$ wide, were measured using a dissecting microscope with a calibrated eyepiece graticule. In this way errors generated by intermediate photographic enlargements were avoided.

Critical pressure of gas vesicles. The critical collapse pressure of gas vesicles of the various cyanobacteria was determined from pressure-sensitive turbidity measurements made with a pressure-nephelometer (Walsby, 1973). Measurements were made with the cells suspended in $0.5 \mathrm{M}$-sucrose, to remove turgor pressure, as described by Walsby (1980). The sucrose solution was supplemented with $5 \mathrm{mM}-\mathrm{K}_{2} \mathrm{HPO}_{4}$ as this was found to improve the stability of the gas vesicles under sustained pressure. Pressure was measured with a $10 \mathrm{~cm}$ diameter test gauge calibrated against a Kistler $5 \mathrm{MPa}$ pressure transducer, which was itself calibrated against a mercury column for pressures of 0 to $0 \cdot 1 \mathrm{MPa}$, and a pressure balance for $0 \cdot 1$ to $2.5 \mathrm{MPa}$. The median critical pressure $\tilde{p}_{\mathrm{c}}$, causing $50 \%$ of the gas vesicles to collapse, was determined from graphs of collapse-pressure curves of the type shown in Fig. 1. The mean critical pressure was calculated as follows. The percentage of gas vesicles collapsing between one pressure and the next was calculated $\left(f_{1}\right)$. The mean of these two pressures $\left(x_{1}\right)$ was determined and the products $f_{1} x_{1}$ and $f_{1} x_{1}^{2}$ calculated. The same procedure was followed for each of the pressure intervals and the sums $\sum f=n$ $(=100), \sum f x$ and $\sum f x^{2}$ were calculated. The mean critical pressure was then $\bar{p}_{\mathrm{c}}=\bar{x}=\sum f x / n$ and standard deviation SD $=\left\{\left[n \sum f x^{2}-\left(\sum f x\right)^{2}\right] / n(n-1)\right\}^{ \pm}$.

Growth of Anabaena flos-aquae with reduced turgor pressure. Cultures were harvested by mild centrifugation and the filaments exposed to a pressure of $1.0 \mathrm{MPa}(10 \mathrm{bar})$ to collapse their gas vesicles. The filaments were then resuspended in culture medium (Walsby $\&$ Booker, 1980) supplemented with sucrose at concentrations of 100,200 and $300 \mathrm{~mm}$ in one experiment and 25, 50,100,125 and $150 \mathrm{~mm}$ in the next. Sucrose, which does not permeate the cells of this species, gave a reduction in cell turgor pressure that was sustained for several days, as recorded previously (Walsby, 1980). These cultures were left to re-form gas vesicles, incubated at $20^{\circ} \mathrm{C}$ under continuous illumination at an incident photon irradiance of $10 \mu \mathrm{mol} \mathrm{m}^{-2} \mathrm{~s}^{-1}$ as measured with a Macam quantum sensor measuring between wavelengths of 400 and $700 \mathrm{~nm}$. Gas vesicle re-formation was monitored by pressure nephelometry. Cell turgor pressure was measured immediately prior to isolation of gas vesicles from these cultures. 
Isolation of the strongest and the weakest gas vesicles. Gas vesicles were isolated from Anabaena flos-aquae and the pressures required to collapse $10 \%$ and $90 \%$ of the gas vesicles in diluted samples of the preparation were determined by pressure nephelometry. Capillary tubes, $3 \mathrm{~cm}$ long and $2 \mathrm{~mm}$ internal diameter, were filled with undiluted samples of the gas vesicle preparation and then inverted under a $2 \mathrm{~cm}$ layer of water in the pressure nephelometer tube. One sample (A) was then exposed to a pressure that would cause $10 \%$ gas vesicle collapse and a second sample (B) to one that would cause $90 \%$ gas vesicle collapse. The water layer over the inverted tubes prevented equilibration of gas vesicles with gas during the pressure rise, which would otherwise have permitted some vesicles to survive supra-critical pressures at the gas-water interface (Walsby, 1971). The two samples, A and B, were then transferred to Eppendorf tubes, where they formed layers of depth $(H) 5 \mathrm{~mm}$, and centrifuged at an acceleration $(\mathrm{g})$ of $1450 \mathrm{~m} \mathrm{~s}^{-2}$ for $2 \mathrm{~h}$. The maximum pressure generated by centrifugation (calculated as $p=H \rho g$ where $\rho$ is the density of the suspension, about $1000 \mathrm{~kg} \mathrm{~m}^{-3}$ ) was therefore only $7.3 \mathrm{kPa}$, much less than the minimum critical pressure of the gas vesicles (about $250 \mathrm{kPa}$ ). The intact gas vesicles that survived previous application of pressure floated at the surface of each sample, forming a layer. The average gas vesicle of Anabaena flos-aquae has a sedimentation constant in water of $-10^{4}$ Svedberg units (A. E. Walsby, unpublished calculations) and would therefore have floated up a distance of $100 \mathrm{~mm}$ under the conditions used, compared with the maximum distance of $5 \mathrm{~mm}$ required to reach the surface. There would not, therefore, have been significant loss of smaller, more slowly floating gas vesicles during this procedure. In the case of sample $B$ these floating gas vesicles were removed in a small volume, resuspended in water and centrifuged again under the same conditions. The procedure was repeated twice. In this way the collapsed gas vesicles were removed from the sample and only the intact ones (representing the strongest $10 \%$ ) remained. In the case of sample $\mathrm{A}$, the clear suspension underneath the white surface layer of intact gas vesicles was removed to a fresh Eppendorf tube, which was also centrifuged under the same conditions. The clear 'subnatant' suspension contained only the collapsed gas vesicles (representing the weakest $10 \%$ ), and was free of contaminating intact ones. The collapsed gas vesicles were then resuspended in phosphate buffer ( $0.01 \mathrm{M}, \mathrm{pH} \mathrm{8.0)}$ layered over a pad of $\mathrm{CsCl}(5.7 \mathrm{M})$ in a $16 \mathrm{ml}$ centrifuge tube and centrifuged at $1.5 \times 10^{6} \mathrm{~m} \mathrm{~s}^{-2}(150000 \mathrm{~g})$ for $3 \mathrm{~h}$. The collapsed gas vesicles, which formed a visible band on the $\mathrm{CsCl}$ pad, were recovered with a microsyringe.

Calculation of gas vesicle dimensions and buoyant densities. The width, $w$, of the collapsed gas vesicle determined by electron microscopy is equivalent to $\pi r$, where $r$ is the cylinder radius (Jost \& Jones, 1970). Hence the cylinder diameter is given by $2 w / \pi$. The cone height, $h$, was not determined separately for each gas vesicle type. For the purpose of the calculations given below it is assumed that $h$ is similar to the mean value in gas vesicles of Anabaena flos-aquae, $52.8 \mathrm{~nm}$. The length of the sloping edge of the cone is calculated from geometrical considerations as $\left(r^{2}+h^{2}\right)^{\frac{1}{2}}$. The length, $l$, of the cylindrical portion of the gas vesicle is given by $L_{\mathrm{c}}-2 s$ if it is assumed that the cones collapse perfectly to sectors of circles of radius $s ; L_{\mathrm{c}}$ is the overall length of the collapsed gas vesicle from collapsed cone tip to cone tip. The ideal end angle of the intact cone is given by $2 \beta=2\left(\tan ^{-1} r / h\right)$ and the complementary base angle is $\alpha=\tan ^{-1} h / r$. The overall volumes of the gas vesicle $(V)$, the wall $\left(V_{w}\right)$ and the contained gas space $\left(V_{\mathrm{i}}\right)$ can be calculated from the equations of Walsby \& Armstrong (1979):

$$
\begin{aligned}
& V=\pi r^{2}\left(l+\frac{2}{3} h\right) \\
& V_{\mathrm{w}}=\pi\left\{l\left(2 r t-t^{2}\right)+\frac{2}{3}\left[r^{2} h-\left(r-\frac{t}{\sin \alpha}\right)^{2}\left(h-\frac{t}{\sin \beta}\right)\right]\right\}
\end{aligned}
$$

and

$$
V_{\mathrm{i}}=V-V_{\mathrm{w}}
$$

where $t$ is the wall thickness. The mean wall thickness of the Anabaena gas vesicle was determined (Walsby \& Armstrong, 1979) by finding the weight of wall protein of known density, $\rho_{\mathrm{w}}=1320 \mathrm{~kg} \mathrm{~m}^{-3}$ (Blaurock \& Walsby, 1976), that surrounded a certain measured gas vesicle gas volume. The value obtained by Walsby $\&$ Armstrong (1979) is improved by substituting in their equations the revised value, $r=42 \mathrm{~nm}$; this yields a value of $t=1.80 \mathrm{~nm}$ for the mean wall thickness. This value is assumed to be the same in gas vesicles of all species; similarly, the buoyant density of the wall protein $\left(\rho_{w}\right)$ is assumed to be the same in all species. (See Hayes \& Walsby, 1986, for the supporting arguments.)

The buoyant density of each type of gas vesicle is calculated as $\rho_{\mathrm{g}}=\rho_{\mathrm{w}} V_{\mathrm{w}} / V$ (see Table 1). The ratio of wall mass to gas volume in each case is calculated as $\rho_{\mathrm{w}} V_{\mathrm{w}} / V_{\mathrm{i}}$, also given in Table 1.

\section{RESULTS}

\section{Gas vesicle dimensions}

The mean lengths and widths of gas vesicles isolated from the eight species (from seven genera) of cyanobacteria are shown in Table 1. From these two dimensions are calculated the average volumes of the gas vesicles, their walls and gas spaces, and the overall densities of the gas vesicles. 


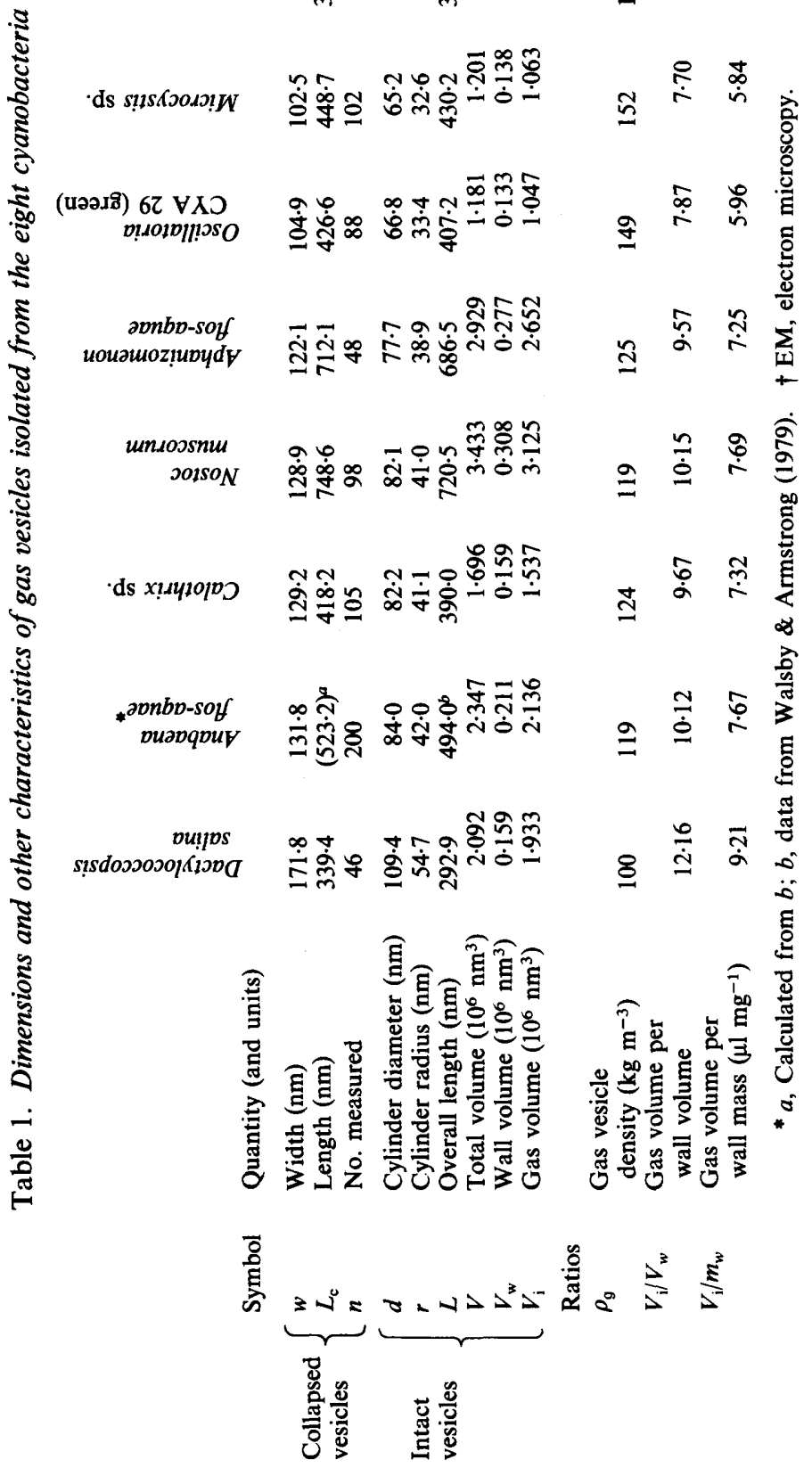


Table 2. Median and mean critical pressures of gas vesicles from the eight cyanobacteria

Cyanobacterium
Dactylococcopsis salina BC 79/1
Anabaena flos-aquae CCAP 1403/13f
Calothrix sp. PCC 7601
Nostoc muscorum PCC 6719
Aphanizomenon flos-aquae CCAP $1401 / 1$
Oscillatoria agardhii NIVA CYA 29 (green)
Microcystis sp. BC 84/1
Oscillatoria agardhii PCC 7801 (red)

Cyanobacterium

Dactylococcopsis salina BC 79/1

Calothrix sp. PCC 7601

Nostoc muscorum PCC 6719

Aphanizomenon flos-aquae CCAP

Oscillatoria agardhii PCC 7801 (red)

\begin{tabular}{|c|c|c|}
\hline \multicolumn{3}{|c|}{ Critical pressure $(\mathrm{MPa})$} \\
\hline Median & Mean & SD \\
\hline 0.31 & 0.33 & $0 \cdot 11$ \\
\hline 0.60 & 0.61 & $0 \cdot 10$ \\
\hline 0.57 & 0.58 & 0.08 \\
\hline 0.56 & 0.57 & 0.08 \\
\hline 0.60 & 0.60 & 0.08 \\
\hline 0.70 & 0.71 & 0.12 \\
\hline 0.77 & 0.77 & 0.12 \\
\hline 0.98 & 0.99 & $0 \cdot 13$ \\
\hline
\end{tabular}

The cylinder diameters of the gas vesicles, calculated from the widths of the collapsed gas vesicles, agree closely (to within $3 \%$ ) with the estimates of diameter made of five of the species listed by Hayes \& Walsby (1986), who calibrated their electron micrograph magnifications by using standardized latex beads. The diameter of the Microcystis sp. gas vesicles, $65.2 \mathrm{~nm}$, is somewhat less than that found for another strain of this genus, $71.6 \mathrm{~nm}$, by Jost \& Jones (1970), who also used a diffraction grating to calibrate the micrograph magnifications. The species are arranged in order of gas vesicle width in Table 1.

There is no apparent relationship between the mean widths and lengths of gas vesicles in the different species. The shortest gas vesicles, those of Dactylococcopsis salina (length $293 \mathrm{~nm}$ ), were the widest, with a diameter of $109 \mathrm{~nm}$, but the next shortest, those of the red-coloured Oscillatoria agardhii PCC 7801 (length $337 \mathrm{~nm}$ ), were the narrowest. Substantially the longest gas vesicles were those of Nostoc muscorum at $720 \mathrm{~nm}$; Waaland \& Branton (1969) reported previously gas vesicles over $1000 \mathrm{~nm}$ in length from this species.

The relative efficiency of the different gas vesicles in providing buoyancy can be gauged by the ratio of gas space to wall volume $\left(V_{\mathrm{i}} / V_{\mathrm{w}}\right.$ in Table 1$)$, a measure of the amount of buoyancy provided by the gas vesicle protein. It is seen that, except for the case of the longest gas vesicles of Nostoc muscorum, this ratio falls in the same order as the gas vesicle width. Thus while the ratio increases with both width and length, it is width that has the dominant effect (see Discussion and Fig. 6).

\section{Critical pressure of gas vesicles, related to their diameter}

The mean critical pressure $\left(\bar{p}_{c}\right)$ of the gas vesicles of each species is shown in Table 2 . The values shown are those obtained for gas vesicles inside cells from which turgor pressure had been removed by addition of $0.5 \mathrm{M}$-sucrose to the culture medium. The values of $\bar{p}_{\mathrm{c}}$ varied from 0.33 MPa for Dactylococcopsis salina to 0.98 MPa for the red-coloured strain of Oscillatoria agardhii, PCC 7801 (Fig. 1). A graph of mean critical pressure versus mean diameter of the gas vesicles from the different species (Fig. 2) shows the inverse relationship between strength and width referred to previously (Walsby, 1972). A double logarithmic plot of these data gives a straight line, as found for the smaller sample analysed by Hayes \& Walsby (1986). Regression analysis gives the relationship

$$
\ln \left(p_{\mathrm{c}} / \mathrm{MPa}\right)=5.62-1.67 \ln (r / \mathrm{nm})
$$

from which we may calculate the expected critical pressure of a gas vesicle of known radius as

$$
p_{\mathrm{c}}=275(\mathrm{r} / \mathrm{nm})^{-1.67} \mathrm{MPa}
$$

The regression coefficient is -0.97 . From the same regression analysis we can calculate the diameter expected for a gas vesicle of a required critical pressure,

$$
d=59.2\left(p_{\mathrm{c}} / \mathrm{MPa}\right)^{-0.561} \mathrm{~nm}
$$

These relationships are used in the following discussion. 


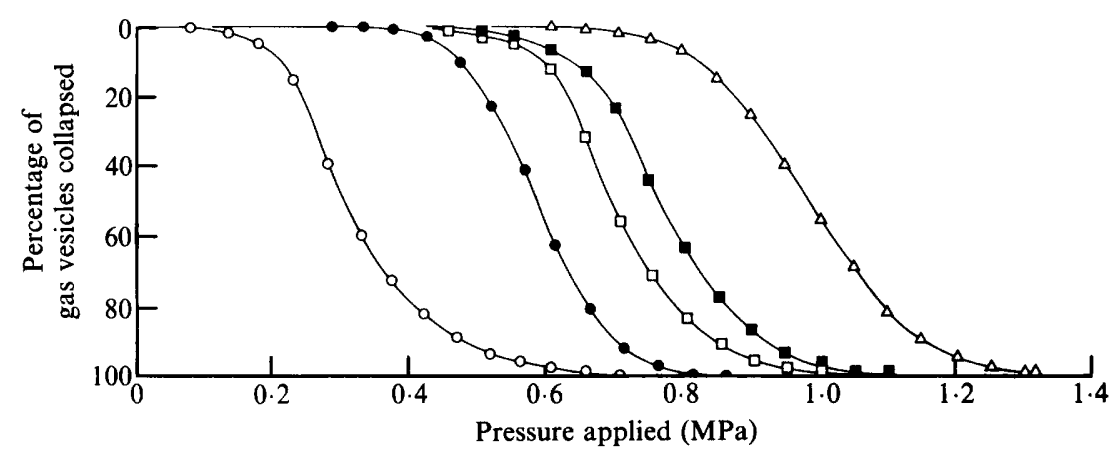

Fig. 1. Distribution of gas vesicle critical pressures in some of the cyanobacteria investigated, illustrating the wide range of variation: Dactylococcopsis salina $(O) ;$ Aphanizomenon flos-aquae (O); green-coloured Oscillatoria CYA $29(\square)$; Microcystis sp. (ם); red-coloured Oscillatoria $7801(\triangle)$.

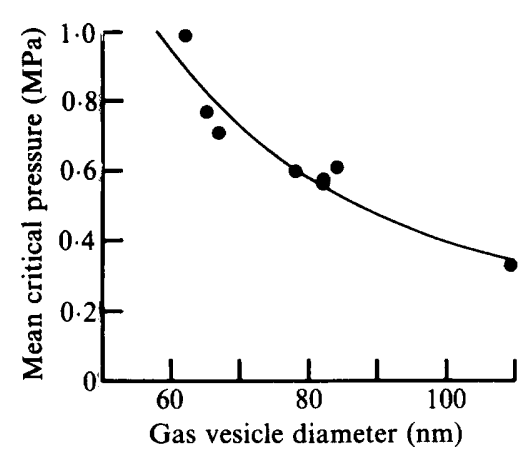

Fig. 2

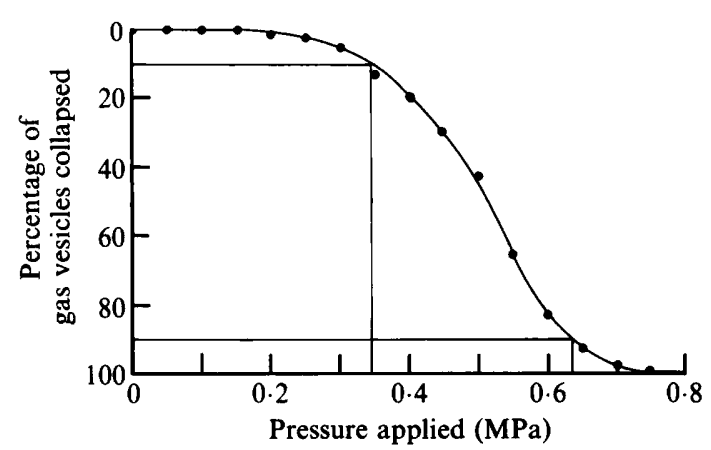

Fig. 3

Fig. 2. The inverse relationship between strength and cylinder diameter of gas vesicles in different cyanobacteria. The line of best fit was calculated from equation (5).

Fig. 3. Critical pressure distribution of gas vesicles isolated from Anabaena flos-aquae, showing pressures subsequently applied to collapse the weakest $10 \%$ and $90 \%$.

\section{Cylinder diameter of gas vesicles with different critical pressure}

The critical pressure distribution of gas vesicles isolated from Anabaena flos-aquae was determined by pressure nephelometry (Fig. 3). (The isolated gas vesicles are slightly weaker $\left(p_{\mathrm{c}}=0.51 \mathrm{MPa}\right)$ than those inside cells, owing to gradual degradation.) From this collapsepressure curve was determined the pressure required to collapse $10 \%$ of the gas vesicles $(0 \cdot 345$ $\mathrm{MPa})$ and $90 \%$ of the gas vesicles $(0.635 \mathrm{MPa})$. These were the pressures then applied, separately, to more concentrated gas vesicle suspensions in capillaries. The distribution of cylinder diameter of the weakest $10 \%$ of the gas vesicles collapsed by the lower pressure was determined by electron microscopy on $n=97$ vesicles (see Fig. $4 a$ ): the mean diameter was $d=85.61 \mathrm{~nm}$, the standard deviation was $\mathrm{SD}= \pm 3.28 \mathrm{~nm}$, and the $95 \%$ confidence limit $(=1.96 \mathrm{sD} / \sqrt{ } n)$ was $\pm 0.65 \mathrm{~nm}$. For the strongest $10 \%$ of the gas vesicles, which survived the higher pressure, measurements on $n=84$ indicated $d=79.38 \mathrm{~nm}, \mathrm{SD}= \pm 3.49 \mathrm{~nm}$ and a $95 \%$ confidence limit of $\pm 0.74 \mathrm{~nm}$ (see Fig. $4 b$ ). Comparison by Student's $t$-test indicated a highly significant difference between the two distributions $(P<0.001)$. Measurements were also made on an unpressurized sample $(n=61)$ in which $d=83.92 \mathrm{~nm}, \mathrm{SD}= \pm 3.36 \mathrm{~nm}$ and the $95 \%$ confidence limit was $\pm 0.84 \mathrm{~nm}$. There was again found to be a significant difference between this and both the weakest $10 \%$ and the strongest $10 \%$ gas vesicle samples $(P<0.001$ in each case). 


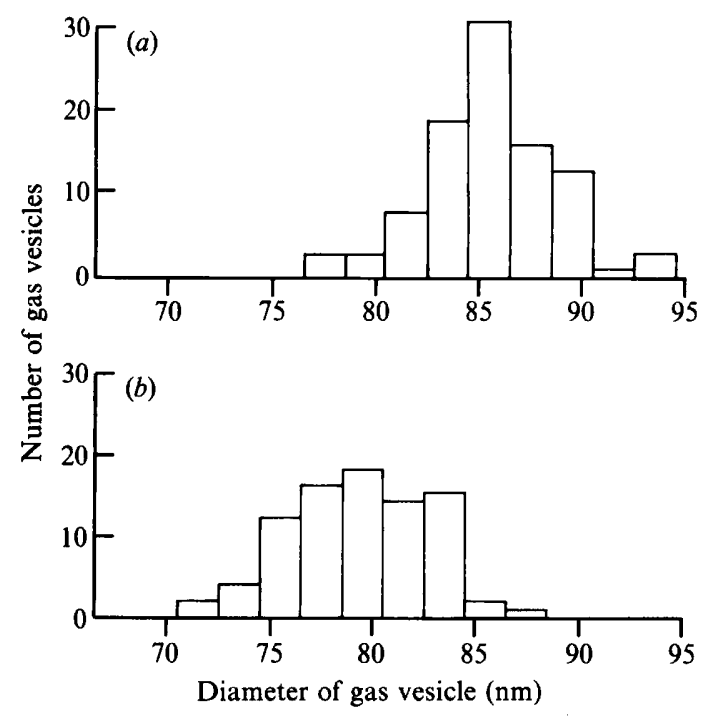

Fig. 4. Distributions of cylinder diameter of gas vesicles isolated from Anabaena flos-aquae: (a) those with the lowest $10 \%$ critical pressure, which were collapsed by a pressure of $0.345 \mathrm{MPa} ;(b)$ those with the highest $10 \%$ critical pressure, which survived a pressure of $0.635 \mathrm{MPa}$.

It can be concluded from the results of this experiment that Anabaena flos-aquae does produce gas vesicles of different diameters and that the range of diameter previously indicated cannot be totally accounted for by measurement error. The experiment also demonstrated that at least part of the range of critical pressure of the gas vesicles in this organism can be explained by differences in cylinder diameter. In an attempt to assess what proportion of the critical pressure variation it accounts for, the following calculation is made.

Analysis of the critical pressure distribution for Anabaena flos-aquae gas vesicles (in cells without turgor pressure, suspended in $0.5 \mathrm{M}$-sucrose) gave the mean critical pressure as $\bar{p}_{\mathrm{c}}=0.615 \mathrm{MPa}$ and standard deviation $\mathrm{SD}=0.095 \mathrm{MPa}$. [The mean critical pressure differs from the median value (pressure giving $50 \%$ collapse) of $0.600 \mathrm{MPa}$, because the distribution is skewed towards the higher pressures.] The critical pressures one standard deviation away from the mean therefore lie at $0.520 \mathrm{MPa}$ and $0.711 \mathrm{MPa}$. Analysis of the cylinder diameter of gas vesicles in cells grown in similar conditions gave $\bar{x}=83.97 \mathrm{~nm}$ and $\mathrm{SD}=4.14 \mathrm{~nm}$, so that the diameters for gas vesicles one standard deviation away from the mean were $79.83 \mathrm{~nm}$ and $88.11 \mathrm{~nm}$. If the cylinder diameter were the only cause of variation in $\bar{p}_{\mathrm{c}}$ we should predict from the relationship given by equation (5) that

when $d=83.97 \mathrm{~nm}, p_{\mathrm{c}}=0.542 \mathrm{MPa}$;

when $d=79.83 \mathrm{~nm}, p_{\mathrm{c}}=0.589 \mathrm{MPa}$, or $0.047 \mathrm{MPa}$ more than that of the calculated value for the mean diameter;

when $d=88.11 \mathrm{~nm}, p_{\mathrm{c}}=0.500 \mathrm{MPa}$, or $0.042 \mathrm{MPa}$ less than that of the calculated value for the mean diameter.

In actuality the critical pressures one standard deviation from the mean differ by $0.095 \mathrm{MPa}$, or twice that predicted by equation (5). It is therefore concluded that variation in width can account for only part of the critical pressure variation.

\section{Gas vesicle formation under reduced turgor pressure}

Samples of the pressure-treated cultures of Anabaena flos-aquae grew, and re-formed gas vesicles, in culture media supplemented with sucrose at concentrations up to $125 \mathrm{~mm}$ but not at higher concentrations. Measurements were made of the median apparent critical pressures $\left(\tilde{p}_{\mathrm{a}}\right)$ of the gas vesicles in these cultures and also of the actual critical pressures $\left(\tilde{p}_{\mathrm{c}}\right)$ determined in samples mixed with equal volumes of $1.0 \mathrm{M}$-sucrose to remove all turgor pressure. The results are 


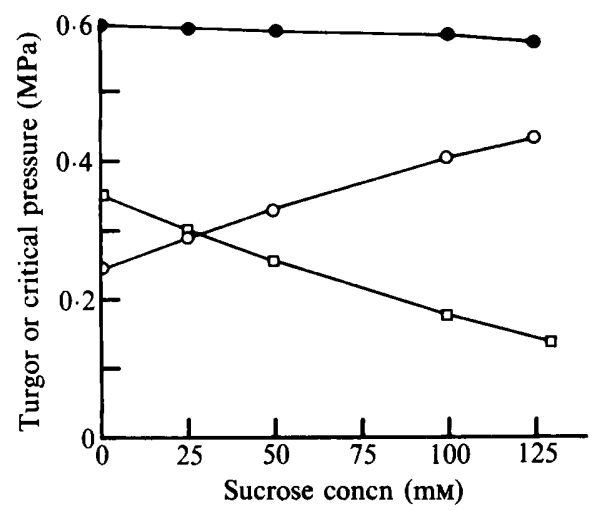

Fig. 5. Median critical pressures of gas vesicles of Anabaena flos-aquae formed in cells grown in medium enriched with sucrose at different concentrations. Critical pressure $\left(\tilde{p}_{\mathrm{c}}\right)$ measured with cells suspended in medium further enriched with $0.5 \mathrm{M}$-sucrose to remove turgor pressure completely; $O$, apparent critical pressure $\left(\tilde{p}_{\mathrm{a}}\right)$ measured with cells in the growth medium used; $\square$, turgor pressure, calculated as $\tilde{p}_{\mathrm{c}}-\tilde{p}_{\mathrm{a}}$.

shown in Fig. 5. The value of $\tilde{p}_{\mathrm{c}}$ decreased slightly with increasing sucrose concentration of the growth medium, from $0.595 \mathrm{MPa}$ at $0 \mathrm{mM}$ to $0.570 \mathrm{MPa}$ at $125 \mathrm{mM}$. The value of $\tilde{p}_{\mathrm{a}}$ showed a marked increase, from $0.243 \mathrm{MPa}$ at $0 \mathrm{mM}$ to $0.433 \mathrm{MPa}$ at $125 \mathrm{mM}$-sucrose, indicating that the cell turgor pressure $\left(p_{\mathrm{t}}=\tilde{p}_{\mathrm{c}}-\tilde{p}_{\mathrm{a}}\right)$ decreased from 0.352 to $0.137 \mathrm{MPa}$ over this range. This result is similar to that obtained previously using cultures in which the original gas vesicles were not collapsed (see Fig. 2 and Table 1 of Walsby, 1980); the turgor pressure falls and is maintained at a lower value because the sucrose does not penetrate the cells of this cyanobacterium, even after several days (Walsby, 1980).

In this experiment the decrease in critical pressure $\left(\tilde{p}_{c}\right)$ of the gas vesicles could be a result of the decrease in turgor pressure under which they formed. A plot of critical pressure versus turgor pressure gives the relationship

$$
\tilde{p}_{\mathrm{c}}=0.558 \mathrm{MPa}+0.106 p_{\mathrm{t}}
$$

with a correlation coefficient of $r=0.97$.

Gas vesicles were isolated from the culture grown in medium enriched with $100 \mathrm{~mm}$-sucrose and their cylinder diameters were determined by electron microscopy. The mean diameter (of $n=84$ gas vesicles) was $\bar{x}=85.56 \mathrm{~nm}$ with $\mathrm{SD}= \pm 3.10 \mathrm{~nm}$ and a $95 \%$ confidence limit of $0.69 \mathrm{~nm}$. Student's $t$-test shows this to be significantly different from the value obtained under normal conditions, at the $P=0.002$ level of probability, although the difference in the mean value is small, only $2 \%$.

We have analysed, as previously, whether the difference in diameter is sufficient to explain the small difference in critical pressure. Using equation (5) it is calculated that for a vesicle of $83.97 \mathrm{~nm}$ diameter the expected $p_{\mathrm{c}}$ is $0.542 \mathrm{PMa}$ whereas for one of $85.56 \mathrm{~nm}$, it is $0.525 \mathrm{MPa}$, a difference of $0.017 \mathrm{MPa}$. This is very close to the difference observed, $0.015 \mathrm{MPa}\left(\tilde{p}_{\mathrm{c}}=0.595\right.$ $\mathrm{MPa}$ in the absence of sucrose, and $0.580 \mathrm{MPa}$ in $100 \mathrm{mM}$-sucrose; see Fig. 5). Thus the increase in diameter can account for all of the decrease in strength. The main point, however, is that a substantial reduction in turgor pressure, which in $100 \mathrm{~mm}$-sucrose is only half that in the absence of sucrose (see Fig. 5), brings about little change in either the diameter or the critical pressure of the gas vesicles that form.

\section{DISCUSSION}

The principal function of the gas vesicle is to provide buoyancy (Walsby, 1972). The amount of buoyancy provided depends on the volume of gas space in the gas vesicle, while the cost of providing this depends on the amount of protein required to surround the gas space. Since the 

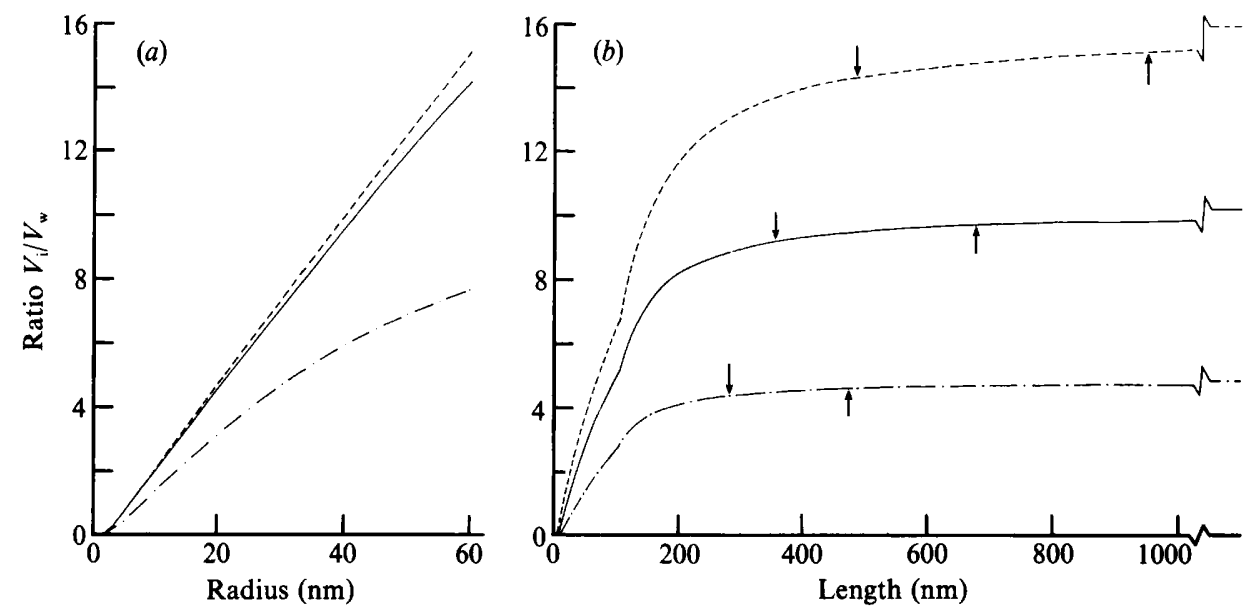

Fig. 6. The ratio of gas volume $\left(V_{\mathrm{i}}\right)$ to wall volume $\left(V_{\mathrm{w}}\right)$ of gas vesicles of various radii $(r)$ and lengths $(L)$. (a) Effect of changing radius for three length classes: $115 \mathrm{~nm}(=2$ cones +2 ribs $)(-\cdot-\cdot) ; 470 \mathrm{~nm}$ (mean for the eight species investigated) (-); and $1000 \mathrm{~nm}$ (about the maximum in most species (----). (b) Effect of changing length for three width classes: radius $20 \mathrm{~nm}(-\cdot-\cdot), 39.4 \mathrm{~nm}$ (mean for the eight species) (-), and $60 \mathrm{~nm}(---)$. The arrows indicate the lengths at which the ratio reaches $90 \%(\downarrow)$ and $95 \%(\uparrow)$ of the value obtained at infinite length.

unit costs of making gas vesicle proteins are likely to be the same, the efficiency of gas vesicles in different organisms must depend on the ratio of gas space to protein, expressed in Table 1 in terms of the ratio of the volumes $V_{\mathrm{i}} / V_{\mathrm{w}}$, calculated by using equations (1), (2) and (3).

Fig. 6(a) shows how the ratio $V_{\mathrm{i}} / V_{\mathrm{w}}$ changes with increasing width. The ratios have been calculated for the cases of gas vesicles of three length classes: $L=115 \mathrm{~nm}$, which is the length of the two conical end caps plus a central cylinder of only two ribs, $L=470 \mathrm{~nm}$, which is the mean length for the gas vesicles of the eight cyanobacteria listed in Table 1 , and $L=1000 \mathrm{~nm}$, about the longest usually encountered. In each case the ratio $V_{\mathrm{i}} / V_{\mathrm{w}}$ increases almost linearly with the cylinder radius $r$. This analysis therefore provides quantitative support for the suggestion that wider gas vesicles enclose more gas space for a given amount of wall material and provide buoyancy at a lower cost (Walsby, 1978). It follows that for reasons of economy natural selection should support the evolution of gas vesicles of the maximum width allowed by the required critical pressure.

Fig. $6(b)$ shows how the ratio of $V_{\mathrm{i}} / V_{\mathrm{w}}$ changes according to length, for three width classes: $r=20 \mathrm{~nm}$, which is slightly less than that of the narrowest gas vesicles known, in Trichodesmium sp. (Gantt et al., 1984), $r=39.4 \mathrm{~nm}$, which is the mean for the eight cyanobacteria in Table 1 , and $r=60 \mathrm{~nm}$, which is slightly more than the radius of the widest, in Dactylococcopsis salina. In each case the initial part of the curve, for lengths up to $106 \mathrm{~nm}$, shows the $V_{\mathrm{i}} / V_{\mathrm{w}}$ ratio for the biconical stages. The method of calculation assumes that the cone height is the same, $h=52.8 \mathrm{~nm}$, in each case, so that the cone angles differ. (It is seen that as the gas vesicles then extend as cylinders the slope of the curve rises more steeply. This occurs because in the method of calculation it is assumed that the wall of the cone has the thickness $t$ measured normal to the plane of the wall, so that its thickness considered normal to the long axis of the gas vesicle is greater by $1 / \sin \alpha$. The actual thickness of the cone wall is not known precisely.) The main points to emerge from this analysis are that as length increases the ratio $V_{\mathrm{i}} / V_{\mathrm{w}}$ increases, and so the efficiency in providing buoyancy increases. The ratio asymptotically approaches a maximum value, however. On each of the curves is indicated, by a downward-pointing arrow, the point at which $V_{\mathrm{i}} / V_{\mathrm{w}}$ reaches $90 \%$ of its maximum value; this occurs at $L=280 \mathrm{~nm}$ for the case of $r=20 \mathrm{~nm}, L=355 \mathrm{~nm}$ for $r=39.4 \mathrm{~nm}$, and $L=485 \mathrm{~nm}$ for $r=60 \mathrm{~nm}$. By similar calculations it can be shown that the mean length of the gas vesicles exceeds the $90 \%$ value for seven of the eight cyanobacteria investigated; the exception is in Dactylococcopsis (see Table 1). 
Previous investigations by Walsby (1971) showed that there was no decrease in critical pressure of Anabaena gas vesicles as they increased in length. Without the penalties of strength encountered with increasing width, the gas vesicles in most of these cyanobacteria achieve lengths that provide buoyancy with high efficiency. In considering why the gas vesicles are not even longer, extracting the last few percent of efficiency, it should be recalled that gas vesicles grow slowly from biconical initials (Waaland \& Branton, 1969; Lehmann \& Jost, 1971) and that the length distribution encountered is that of a population of gas vesicles in various stages of maturation. In each case (except Dactylococcopsis) the longest (and hence oldest) gas vesicles encountered have a $V_{\mathrm{i}} / V_{\mathrm{w}}$ ratio exceeding $95 \%$ of the maximum for the width class. There are also, of course, space limitations on the length of the gas vesicles that can be accommodated in the cells of some of these cyanobacteria. It is also possible that very long gas vesicles might be more easily damaged during the cytoplasmic movements that must occur during cell division.

We have demonstrated that the width of the gas vesicles in Anabaena flos-aquae does vary, with the diameter of the weakest $10 \%$ being on average over $6 \mathrm{~nm}$ wider than that of the strongest $10 \%$. The width of the gas vesicle is, in a sense, determined by the number of gas vesicle protein (GVPa) molecules that form each rib of the structure. In Anabaena flos-aquae, molecules of the major protein $(\mathrm{GVPa})$ form a periodic repeat at intervals of $1.15 \mathrm{~nm}$ along the ribs (Blaurock \& Walsby, 1976). A rib of $84 \mathrm{~nm}$ diameter therefore contains $229 \mathrm{GVPa}$ molecules, and there will, on average, be 17 more GVPa molecules present in the rib of the weakest gas vesicles compared to the strongest ones. It is clear, then, that gas vesicle width in this species is not specified by a precise, invariable number of protein molecules, in the way that the width of the tobacco mosaic virus is (Klug, 1972), but rather it would appear that there is a loose preference for the molecules to assemble into ribs of certain size. This may be determined by the shape of the GVP molecule (Walsby, 1978), which will be a product of its amino acid sequence. It might eventually be possible to test this idea by transferring the genes for gas vesicle proteins (Tandeau de Marsac et al., 1985; Damerval et al., 1987) from different cyanobacteria into some other organism in which the genes are expressed and the proteins assembled into gas vesicles.

We have recently demonstrated that in Anabaena flos-aquae there is, in addition to the main protein GVPa, a second protein, GVPc, which forms $9 \%$ of the mass of the gas vesicle (Hayes et $a l ., 1988$ ). This minor component (which is homologous with the gene product of $g v p C$ isolated by Damerval et al., 1987, from Calothrix) is located on the outer surface of the Anabaena gas vesicle and its removal results in a marked decrease in critical pressure of the structure (Walsby \& Hayes, 1988). It therefore appears that the association of GVPc with the gas vesicle inside cells may be one of the factors that accounts for the part of the variation in critical pressure not explained by variation in cylinder diameter, as discussed above.

It has been shown that the critical pressure of gas vesicles in different organisms, and within Anabaena flos-aquae, is inversely correlated with the width of the structure, but changing the hydrostatic pressure (in the form of turgor pressure) has little effect on the width of gas vesicles that form under it. What is proposed is that hydrostatic pressure in the natural habitat influences the natural selection of gas vesicles of different critical pressures, and hence of different widths according to the relationship described in equation (6). The principle can be illustrated by reference to the gas vesicles of the two extremes. The gas vesicles of Dactylococcopsis salina are strong enough $\left(\bar{p}_{\mathrm{c}}=0.33 \mathrm{MPa}\right)$ to withstand the combination of turgor pressure and hydrostatic pressure (0.14 MPa) in Solar Lake, Sinai, where this organism grows (Walsby et al., 1983a). If such gas vesicles were to be produced in the cells of the red Oscillatoria agardhii from Lake Gjersjøen, Norway, however, over half of them would be coilapsed by turgor pressure alone $(0.36 \mathrm{MPa})$, and the remainder would be collapsed by the hydrostatic pressure $(>0.4 \mathrm{MPa})$ generated at holomixis (Walsby et al., 1983b). It is therefore clear why gas vesicles that are narrower and stronger $\left(\bar{p}_{\mathrm{c}}=0.99 \mathrm{MPa}\right)$ have evolved in this strain of Oscillatoria. Considering the reverse situation, gas vesicles from the Oscillatoria produced in the cells of Dactylococcopsis in Solar Lake would obviously survive the lower pressures, but they would require the production of $70 \%$ more gas vesicle protein to provide the same amount of gas space for buoyancy (see Table 1). We therefore see why gas vesicles that are wider and more efficient have 
evolved in Dactylococcopsis. It is proposed that in each of the other organisms described, the evolved morphology of the gas vesicles has been similarly influenced by the requirement for a particular critical pressure.

This work was supported by the NERC with a research grant to A. E. Walsby and a studentship to A. Bleything. We thank Miss Annette Bees for providing cultures of cyanobacteria, Dr P. K. Hayes for discussion and advice on techniques, and Miss A. Bird for preparing the typescript.

\section{REFERENCES}

Armstrong, R. E., Hayes, P. K. \& Walsby, A. E. (1983). Gas vacuole formation in hormogonia of Nostoc muscorum. Journal of General Microbiology 129, 263-270.

Blaurock, A. E. \& Walsby, A. E. (1976). Crystalline structure of the gas vesicle wall from Anabaena flosaquae. Journal of Molecular Biology 105, 183-199.

Bowen, C. C. \& JENSEN, T. E. (1965). Blue-green algae: fine structure of the gas vacuoles. Science 174, 1460-1462.

Damerval, T., Houmard, J., Guglielmi, G., CsisZAR, K. \& TANDEAU DE MARSAC, N. (1987). A developmentally regulated gvpABC operon is involved in the formation of gas vesicles in the cyanobacterium Calothrix 7601. Gene 54, 83-92.

GantT, E., OHKI, K. \& FujITA, Y. (1984). Trichodesmium thiebautii; structure of a nitrogen-fixing marine blue-green alga (Cyanophyta). Protoplasma 119, 188196.

Hayes, P. K. \& Walsby, A. E. (1986). The inverse correlation between width and strength of gas vesicles in cyanobacteria. British Phycological Journal 21, 191-197.

Hayes, P. K., Lazarus, C. M., Bees, A., Walker, J. E. \& WALSBY, A. E. (1988). The protein encoded by $g v p C$ is a minor component of gas vesicles isolated from the cyanobacteria Anabaena flos-aquae and Microcystis sp. Molecular Microbiology (in the Press).

Jost, M. (1965). Die Ultrastrucktur von Oscillatoria rubescens D.C. Archiv für Mikrobiologie 50, 211-245.

JosT, M. \& JoNES, D. D. (1970). Morphological parameters and macromolecular organization of gas vacuole membranes of Microcystis aeruginosa Kuetz. emend. Elenkin. Canadian Journal of Microbiology 16, 159-164.

KLUG, A. (1972). Assembly of tobacco mosaic virus. Federation Proceedings 31, 30-42.

LehmanN, H. \& Jost, M. (1971). Kinetics of the assembly of gas vacuoles in the blue-green alga Microcystis aeruginosa Kuetz. emend. Elenkin. Archiv für Mikrobiologie 79, 59-68.

RipPKa, R., Deruelles, J., Waterbury, J. B., Herdman, M. \& Stanier, R. Y. (1979). Generic assignments, strain histories and properties of pure cultures of cyanobacteria. Journal of General Microbiology 111, 1-61.

SmITH, R. V. \& PeAT, A. (1967). Comparative structure of the gas-vacuoles of blue-green algae. Archiv für Mikrobiologie 57, 111-122.

Tandeau de Marsac, N., Mazel, D., Bryant, D. A. \& Houmard, J. (1985). Molecular cloning and nucleotide sequence of a developmentally regulated gene from the cyanobacterium Calothrix PCC 7601 : a gas vesicle protein gene. Nucleic Acids Research 13, 7223-7236.

WAaland, J. R. \& Branton, D. (1969). Gas vacuole development in a blue-green alga. Science 163, 13391341.

Walker, J. E., Hayes, P. K. \& Walsby, A. E. (1984). Homology of gas vesicle proteins in cyanobacteria and halobacteria. Journal of General Microbiology 130, 2709-2715.

WALSBY, A. E. (1971). The pressure relationships of gas vacuoles. Proceedings of the Royal Society of London B178, 301-326.

WaLSBY, A. E. (1972). Structure and function of gas vacuoles. Bacteriological Reviews 36, 1-32.

WalSBY, A. E. (1973). A portable apparatus for measuring relative gas vacuolation, the strength of gas vacuoles, and turgor pressure in planktonic bluegreen algae and bacteria. Limnology and Oceanography 18, 653-658.

WALSBY, A. E. (1974). The isolation of gas vesicles from blue-green algae. Methods in Enzymology 31A, 678-686.

WALSBY, A. E. (1978). The gas vesicles of aquatic prokaryotes. In Relations between Structure and Function in the Prokaryotic Cell, pp. 327-358. Edited by R. Y. Stanier, H. J. Rogers \& J. B. Ward. Cambridge: Cambridge University Press.

WALSBY, A. E. (1980). The water relations of gasvacuolate prokaryotes. Proceedings of the Royal Society of London B208, 73-102.

Walsby, A. E. \& Armstrong, R. E. (1979). Average thickness of the gas vesicle wall. Journal of Molecular Biology 129, 279-285.

WALSBY, A. E. \& BOOKER, M. J. (1980). Changes in buoyancy of a planktonic blue-green alga in response to light intensity. British Phycological Journal 15, 311-319.

Walsby, A. E. \& Hayes, P. K. (1988). The minor cyanobacterial gas vesicle protein, GVPc, is attached to the outer surface of the gas vesicle. Journal of General Microbiology 134, 2647-2657.

WalsbY, A. E., VAN RIJN, J. \& Cohen, Y. (1983a). The biology of a new gas-vacuolate cyanobacterium, Dactylococcopsis salina sp. nov., in Solar Lake. Proceedings of the Royal Society of London B217, 417447.

Walsby, A. E., UtKilen, H. C. \& Johnsen, I. J. $(1983 b)$. Buoyancy changes of a red coloured Oscillatoria agardhii in Lake Gjersjøen, Norway. Archiv für Hydrobiologie 97, 18-38. 